\title{
Cortisol and Cardiac Reactivity in the Context of Sex Discrimination: The Moderating Effects of Mood and Perceived Control
}

\author{
Kimberly Matheson*, Ritu Gill, Owen Kelly and Hymie Anisman \\ Department of Psychology and Institute of Neuroscience, Carleton University, Ottawa, Canada
}

\begin{abstract}
The high incidence of stressor-related pathologies among stigmatized groups has been associated with experiences of discrimination. The present study demonstrated that following a mood priming manipulation (anger vs. sadness), an acute sex discrimination event influenced women's $(\mathrm{N}=61)$ salivary cortisol levels as well as systolic (SBP) and diastolic (DBP) blood pressure. Among women primed to feel sad, cortisol levels declined over the course of the experimental session, likely reflecting a decline of arousal. However, among those primed to feel angry the cortisol levels were sustained over the session, especially if they perceived the possibility of rectifying their failed status (control). As well, SBP and DBP increased following the discrimination experience irrespective of perceived control. Among women primed to feel angry, feelings of hostility were associated with higher SBP and heart rate. Evidently, sex discrimination affects stress-reactive physiological systems among women, and might thus influence vulnerability to pathology.
\end{abstract}

Key Words: Sex discrimination, anger, hostility, perceived control, cortisol, cardiovascular reactivity.

\section{INTRODUCTION}

Members of stigmatized or otherwise socially-devalued groups (e.g., women, Blacks, gays, First Nations people) suffer disproportionately from stressor-related psychological (e.g., depression, posttraumatic stress disorder) and physiological disturbances (e.g., immune dysfunction, diabetes, cardiovascular illness) [1-7]. Although numerous factors might contribute to pathology (e.g., genetic, cultural, experiential, and socioeconomic), experiences of discrimination may represent a source of daily and even traumatic stressors [8-11] that favor the evolution of stress-related disturbances.

The distress related to discrimination, like that associated with other stressors, might be expected to promote activation of neuroendocrine and autonomic systems. In this regard, hypothalamic-pituitary-adrenal (HPA) activation, together with sympathetic arousal, may serve in multiple adaptive capacities to deal with threats $[12,13]$. However, when stressors occur on a persistent basis, these biological systems may become overly taxed (allostatic overload), hence favoring pathological outcomes $[14,15]$. Although there is ample reason to consider discrimination as a potent stressor, there is scant information regarding the impact of discrimination on HPA activity, and the empirical findings supporting the detrimental impact of discrimination on cardiovascular responses have been inconsistent [cf. 2, 16-21].

The present investigation was conducted to assess cortisol and cardiovascular reactions to an acute instance of sex discrimination against women in a controlled laboratory setting. Of course, not all members of devalued groups demonstrate stress-related disturbances, and individual difference factors, including pre-existing or antecedent mood states, might influence responses to discrimination [22]. As anger is

*Address correspondence to this author at the Department of Psychology, Carleton University, Ottawa, Ontario, Canada, K1S 5B6; Tel: (613) 5203570; Fax: (613) 520-3945; E-mail: kim_matheson@carleton.ca a common response to discrimination [23], in the present investigation, women's stress responses were considered in relation to experimentally primed anger (vs. sadness). Moreover, as perceptions of controllability may influence stressor-provoked physiological reactivity [24-26], it was of interest to establish whether perceptions of an aspect of control would influence neuroendocrine and cardiovascular reactions. In this regard, the occurrence of discrimination is inherently beyond victims' control; however, perceptions of control over rectifying the situation may vary, and may be pivotal to subsequent responses. Thus, we assessed whether stressor-reactive processes were influenced by women's perceptions that their failure due to discrimination was rectifiable.

\section{PREPOTENT MOOD STATES: THE ROLE OF AN- GER}

When group members encounter discrimination, the most common behavioral response is one of acceptance (e.g., diminishing its importance) $[27,28]$. Yet, the emotion most frequently elicited in response to overt experiences of discrimination is that of anger [23,29-31], which serves as a catalyst for actions to confront the discrimination [23,32]. It seems, however, that unless anger is accompanied by perceptions that actions might alter the situation, effortful strategies, such as confrontation are less likely to be used $[33,34]$.

Although emotions are typically viewed as the outcome of appraisals of stressors, the relations between emotions and appraisals are dynamic and reciprocal [35,36]. Indeed, it seems that pre-existing affective states, including anger, may influence cognitive and behavioral reactions to discriminatory events [32,36-38]. Antecedent emotional states may emanate from a range of factors, including sensitivity to discrimination and perceptions that it is pervasive [39,40], features of the situation itself (e.g., availability of social support) [23,34], as well as dispositional characteristics (e.g. coping styles) [30]. Whatever the source of the antecedent 
mood state, there is reason to believe that it might contribute to group members' reactions to discrimination, including effects on physiological stress reactivity.

\section{Cortisol Reactivity}

Activation of HPA functioning, culminating in elevated circulating cortisol levels, is elicited in response to a variety of naturalistic and laboratory stressors [25,41-43]. Typically, acute stressors promote a cascade of neurochemical changes that enhance the effects of other neuroendocrine processes, prepare the organism to deal effectively with current or impending stressors, and blunt its physiological and psychological impact $[13,15,44]$. However, as indicated earlier, when the stressor is sufficiently protracted and unpredictable, the wear and tear on endogenous systems may become excessive, thereby increasing vulnerability to a variety of pathological states $[14,15]$.

Meta-analyses of stressors on cortisol reactivity in humans, revealed that the experience of a social threat, coupled with a sense of uncontrollability in relation to task demands, and chronicity of the stressor, were key to evoking cortisol elevations $[25,42,43]$. In most stress research, controllability is defined in terms of outcomes being contingent on responses. In the case of discrimination, however, it is often the case that group members have no control over the occurrence of the event, but may perceive control or efficacy in terms of rectifying or confronting the situation [33,34]. In this sense, individuals' perceptions that they may be able to confront the situation, combined with the activating properties of anger, might actually favor increased cortisol release as part of a response to actively engage with an ongoing stressor situation (i.e., confronting the perpetrator remains a possibility).

\section{Cardiac Reactivity}

In contrast to HPA variations, considerably more is known about the relations between minority group membership, self-reports of discrimination, and cardiovascular functioning. Autonomic reactivity is highly stress responsive [4547], but the magnitude of the response may be influenced by psychosocial factors, such as hostility [48-51], and perceptions of self-efficacy and control [26,52]. In general, laboratory stressors have been associated with increased heart rate, systolic blood pressure (SBP), and diastolic blood pressure (DBP), although stress reactivity may vary as a function of situational factors, such as whether the task is socially competitive [53], or personally threatening [54], both of which may be features of discrimination. Although elevated cardiac reactivity, like HPA activation, can act in an adaptive capacity $[15,55]$, prolonged sympathetic arousal may increase vulnerability to negative health outcomes [56-58].

Anger may serve as a trigger to cardiac reactivity, which when experienced repeatedly may have detrimental effects on cardiovascular functioning [22,59]. Indeed, anger-provoking and racist situations elicited increased DBP among men, and among African American men these levels remained elevated for sustained periods [60-61]. Possibly related to chronic anger, a consistent relation has been documented between hostility and increased cardiovascular reactivity and risk of cardiovascular disease [48,49,50,51]. Although hostility and anger might both serve to increase car- diovascular reactivity [56], they might also operate independently of one another $[48,62]$. Specifically, hostility as a trait characteristic may be linked to increased cardiovascular reactivity in the absence of anger, but anger superimposed upon hostility may result in an exaggerated cardiovascular response [48].

To a considerable extent, research regarding discrimination and cardiovascular disease has focused on African Americans. It ought to be recognized that cardiovascular disease is the foremost mortality factor among women, and has been linked to factors such as tobacco use, atherogenic diet, obesity, sedentary lifestyle, hypertension, diabetes mellitus, as well as elevated C-reactive protein [63,64]. Given that women encounter a variety of stressors not experienced by men, including those emanating from discrimination, the possibility exists that factors primarily or secondarily related to sex discrimination contribute to the high incidence of cardiovascular disease. In this regard, a history of discrimination or exposure to discrimination cues increased diastolic blood pressure, along with slower normalization, in response to a stressor among African American women [17, 65]. However, in general, information is lacking concerning the impact of sex discrimination on cardiovascular reactivity.

\section{THE PRESENT INVESTIGATION}

The present investigation assessed the impacts of anger on cortisol and cardiac reactivity in the context of an instance of blatant gender discrimination against women. Much of the research examining the relations between discrimination experiences and well-being has employed selfreport measures $[3,5,6,17,21]$. However, members of stigmatized groups may not report personal experiences of discrimination, even when independent confirmation exists that they had been objectively disadvantaged due their group membership [66-69]. Given this under-reporting bias, assessment of the relations between self-reported discrimination and well-being is problematic [70,71]. Thus, in the present investigation, participants were exposed to an acute discriminatory event in a controlled laboratory context. To maximize generalizability to real life experiences, and yet achieve control over the objective conditions of the event, a simulation paradigm was employed in which failure in a competitive performance-based task was reliably attributed to discrimination [32].

To determine its causal role, anger was primed in advance of the discrimination event. Although anger is often elicited by discrimination, priming mood maximizes the degree to which it might be experienced, while minimizing the role of other individual difference processes (e.g., threat sensitivity) that might otherwise influence the relation between anger and physiological outcomes. Ordinarily, the obvious control group would be a no mood-prime condition; however, given the predominance of anger in response to discrimination in the absence of any mood prime [23,31], in this instance, a more appropriate control condition would be one in which an alternative affective state was primed that might have the effect of mitigating anger. Thus, based on our past research [32], a comparison group of women was primed to feel sadness, as this emotion entails negative affect, but does not have the activating properties of anger [72]. It was hypothesized that: 
1) women primed to feel anger would demonstrate higher cortisol levels, and higher systolic blood pressure (SBP), diastolic blood pressure (DBP), and heart rate following a discrimination event, relative to women primed to feel sad.

2) high levels of hostility would be linked to increased cardiovascular reactivity following discrimination; this relation may be exacerbated among women primed to be angry.

3) perceptions of control in relation to rectifying their failed status would moderate the effects of mood prime. Specifically, among women primed to feel angry, perceived control would be associated with increased cortisol reactivity, but this would not be the case when women were primed to feel sad.

\section{METHOD}

\section{Participants}

First year female university students were recruited $(N=$ $61 ; M$ age $=20.6$ years, $S D=3.9$ ) for a study examining storytelling abilities, for which they received experimental credit and eligibility to participate in a $\$ 100$ lottery. The majority of women self-reported their ethnic status as EuroCaucasian $(n=49,80.3 \%)$, with the remainder indicating that they were of African $(n=4 ; 6.6 \%)$, Asian $(n=7 ; 11.5 \%)$, or Middle-Eastern $(n=1)$ descent. This distribution is typical of studies we have conducted at this Canadian institution. Exclusion criteria included current use of any neuroleptics or who were taking drugs that could affect cortisol levels (e.g., antihistamines). Ten participants were currently taking some form of anti-depressant or anti-anxiety medication; use of these medications was associated with slightly higher baseline levels of SBP $(p=.026)$. Over half of the women $(n=36)$ were taking oral contraceptives, but their use was not significantly related to baseline levels of cortisol or the cardiac measures. Thus, women on these medications were retained in the analyses; however, the direct and moderating effects of drug use were examined, and where significant, the effects of these variables were reported.

\section{Procedures}

Following a brief overview of the procedures, including those involving the collection of saliva samples and blood pressure readings, written informed consent was obtained. Participants were told that sometimes stress might influence performance, and that the biological measures represented an objective index of their stress levels. All women individually completed a brief background questionnaire, the Beck Depression Inventory ${ }^{1}$, and the irritability and verbal hostility subscales from the Buss-Durkee Hostility Inventory. Women then completed a short story writing task. The real purpose of this task was to 1) prime a particular mood, and 2) set the stage to enact a situation of discrimination [32]. A female experimenter told participants that the purpose of the study was to identify factors that contribute to logical and creative

${ }^{1}$ Beck depression scores (13-item version; [87]) were evaluated to determine whether depressive symptoms altered physiological reactivity and recovery rates. These scores were unrelated to all of the physiological indices, and did not moderate any of the experimental effects, and hence were not reported in the present analyses. abilities that were important to success in many organizational contexts. Women were told that their stories would be scored, and if they exceeded a predetermined criterion they would be assigned to the high status (high ability) group, whereas if they did not, they would be categorized in the low status (low ability) group. The experimenter further explained that the subsequent task of the high status group would be to improve the stories of the less able participants, whereas those in the low status group would perform a second writing task, as well as a number of tedious exercises (alphabetizing, sentence completion) to assess the relation between their lack of ability on the task and other language and writing deficits. Allegedly, those who qualified for the high status group would be eligible to participate in a $\$ 100$ lottery and receive full experimental credit, whereas those in the low status group would participate in a $\$ 10$ lottery and would only receive half of their experimental credit. These manipulations have been found to be effective in past research wherein the intent was to provide sufficient incentive to make the two groups differentially desirable [28,32,72]. In reality, all women received full compensation, and none of the subsequent tasks were conducted.

The writing task comprised reading a story describing an achievement failure situation in which a student received a poor grade and meets with the professor who is unwilling to change the grade [from 73]. After reading this scenario, participants recreated and extended the story in their own words with themselves as the protagonist using a list of 12 target words, five of which constituted the mood manipulation. Women were randomly assigned to one of two wordlist conditions that primed (1) sadness; relevant words were sad, hopeless, discouraged, helpless, despair, or (2) anger; including angry, hostile, infuriated, irritated, resentful. In our past research, we found this manipulation to effectively induce the relevant mood state relative to a no mood-prime control group [32].

Following this task, a male confederate collected the participant's story and indicated that he would be bringing it next door to be scored by a (alleged) jury of male students from the engineering department who were learning about psychological research methods (a likely scenario, given a collaborative degree program between engineering and psychology). While waiting for their story to be scored, participants completed a filler task in which they wrote about an event that made them feel very sad or angry, respectively. This served to maintain or enhance the mood primed while the stories were allegedly being scored. Following this second task, women completed a mood manipulation check. Upon return, the male confederate handed back the woman's story (marked LOW), and as he did so, he commented, "These guys never pass any of the women". He then reminded the participant of the implications of belonging to the low status group (i.e., the subsequent tasks and reduced compensation).

After the discrimination event, women completed a measure of perceived discrimination and perceptions of control (imbedded among other items). They were then debriefed, and a positive mood induction procedure was applied. Once told of the true purpose of the study, women completed a second informed consent permitting the use of their data. 


\section{Salivary Cortisol}

Women provided saliva samples for the determination of cortisol levels. This comprised placing a piece of dental cotton in the cheek for a 2 min period. Once the cotton was thoroughly wet, it was placed in a 'salivette' for subsequent analysis. This procedure was conducted 3 times: baseline levels were assessed $15 \mathrm{~min}$ after arriving to the experimental session, and then again at $15 \mathrm{~min}$ and $30 \mathrm{~min}$ following the discrimination event, but prior to debriefing. These times were chosen as they represent the peak levels of cortisol in saliva following a stressor event [74]. In the present investigation, participants were tested between 10:30 and 17:30 hours, with the majority of participants being run in the afternoon $(n=45 ; 73.8 \%)$. Given that cortisol levels ordinarily vary over the course of a day, where appropriate time of day was considered as a covariate, along with whether it interacted with the other predictors of cortisol levels. Salivary cortisol levels were determined, in duplicate, by means of a solid phase radio-immuno assay using ${ }^{125}$ I kits (ICN Biomedicals Inc., CA). The intra- and extra-assay variability was less than $10 \%$.

\section{Cardiovascular Activity}

SBP, DBP, and heart rate were recorded at 4 times: baseline, immediately following the mood priming procedure, immediately (1 $\mathrm{min})$ and $30 \mathrm{~min}$ following the discrimination event. Readings were taken using an automatic inflation wrist cuff monitor (LifeSource, Milpitas, CA) that maintained BP scores in memory. The cuff was wrapped around participants' left wrist, and they were seated comfortably with their arm resting on the table.

\section{Measures}

\section{Mood}

To assess the effectiveness of the mood priming manipulation, women rated their mood (using 1-7 scales) along 19 mood adjectives. A principle components analysis suggested the presence of three factors, based on a parallel analysis comparing actual eigenvalues to eigenvalues generated from a random data set [75]. Consideration of loadings greater than .45 following a varimax rotation indicated that these factors tapped into feelings of sadness (sad, unhappy, depressed, helpless, hopeless, desolate, confused, anxious and worried) $(\alpha=.81)$, anger (angry, frustrated, hostile, infuriated) $(\alpha=.70)$, and positive affect (happy, relaxed, pleased, calm, indifferent) $(\alpha=.84)$. Levels of positive affect were mildly negatively related to sadness $(r=-.24, p=.06)$ but not anger $(r=-.12, n s)$, and the latter two factors were not related $(r=.03, n s)$.

\section{Perceptions of Discrimination}

Women rated the "extent you were personally discriminated against because you are a women in the context of this experiment", and the "extent you feel that women as a group were discriminated against in the context of this experiment", on 1 (not at all) to 7 (extremely) rating scales [76]. Responses were averaged, such that higher scores reflected greater perceived discrimination, $r=.71, p<.001$.

\section{Perceptions of Control}

Perceived control was assessed using a measure that had been designed for use in a paradigm similar to that of the present study [77]. Women responded to items assessing their perceptions of control regarding whether they'd be able to overcome their failed status based on their personal performance (e.g., "How likely is it that you would be placed in the high creativity group if you did this task again and had the same primary experimenter read your story?"), and through social aspects of the experiment (e.g., "Do you think that by meeting the primary experimenter in person you could get him to judge you solely on the quality of your work?"). Responses were rated on an 8-point scale ranging from 0 (not at all) to 7 (very likely). Five items formed a reliable scale, such that higher scores reflected perceptions of greater control $(\alpha=.69)$.

\section{Hostility}

The Buss-Durkee Hostility Inventory [78] is a widely used instrument to assess hostility. The 25 items comprising the subscales of irritability and verbal hostility were viewed as most relevant for administration in the present investigation. These items formed a highly reliable index of hostility $(\alpha=.97)$.

\section{Statistical Analysis}

To assess whether the mood prime manipulation (angry vs. sad) influenced women's perceptions of discrimination and control, independent groups t-tests were employed. Mood prime was then crossed with within-subject variables in a factorial mixed-group analysis of variance (ANOVA) design to assess (1) differential effects on self-reported mood (sad, angry, positive affect; within subjects) and (2) variations in cortisol and cardiac measures across time (withinsubjects). Simple effects analyses entailed pairwise comparisons using Bonferroni corrections for family wise error $(\alpha=.05)$. In each instance, the possibility that time of day, use of oral contraceptives, or use of anti-depressant or antianxiety drugs might serve either as covariates or moderating variables was considered; only when these factors played a significant role were the results reported.

To assess the moderating effects of hostility and perceptions of control on cortisol and cardiac indices, hierarchical regressions were conducted. The outcome variables were represented by proportional change (ratio) scores; these were calculated by dividing values following the discrimination event by baseline levels measured 15 min after participants arrived at the laboratory. In so doing, any individual difference variations (e.g., due to time of day) were controlled for, and hence any effects likely reflected events occurring within the experimental session. For each regression, the moderator variable of interest (hostility, perceived control) was entered on the first step. The main effect of mood prime was entered on the second, followed by the 2-way interactions (cross-product) between the moderating variable and mood prime.

\section{RESULTS}

\section{Manipulation Checks}

Predictably, in a 2 (mood prime) x 3 (self-reported mood) mixed measures ANOVA, the main effect for self-reported mood was significant, $F(2,118)=135.13, p<.001, \eta^{2}=.696$. Follow-up comparisons indicated that women reported lower levels of positive affect than either sadness or anger 
( $p s<.01)$. In addition, as expected, a significant interaction between mood prime and self-reported mood was evident, $F(2,118)=8.08, p<.001, \eta^{2}=.120$. In line with the mood manipulations, women primed to feel sad reported lower levels of anger $(M=3.73, S D=0.85)$ and higher levels of sadness $(M=4.74, S D=0.88)$, than did women who were primed to feel angry (anger $M=4.49, S D=1.17$; sadness $M=4.08$, $S D=0.95), p s<.01$. There was no difference in levels of positive affect reported by women in the two mood prime groups $(M=1.76, S D=0.86)$. Based on these analyses, it appeared that the mood priming manipulation was effective.

Women's perceptions of discrimination did not vary as function of mood primed, $t(59)=-0.49, n s$. On the whole, women reported that the experience was moderately discriminatory $(M=3.15, S D=2.10)$, and this level of perceived discrimination differed significantly from 0 (not at all), $t(60)=11.71, p<.001$. Finally, there was no difference as a function of mood prime in levels of perceived control $(M=2.64, S D=1.47), t(59)=-.04, n s$.

\section{Physiological Reactions}

\section{Cortisol}

To assess whether cortisol reactivity varied as a function of mood prime, cortisol levels (at baseline, 15 and $30 \mathrm{~min}$ following the discrimination) were examined in a mixed measures ANOVA. Current use of an anti-depressant or antianxiety was a significant covariate, $F(1,49)=4.90, p<.05$. After controlling for drug use, there was a significant interaction between mood prime and time of measure, $F(2,98)$ $=3.50, p<.05, \eta^{2}=.067$. Specifically, as seen in Fig. (1), among women primed to feel sad, cortisol levels declined over the course of the test session, likely reflecting relaxation related to test anxiety. In contrast, this decline was not evident among women primed to feel angry, suggesting that the arousal and the related HPA activation was maintained.

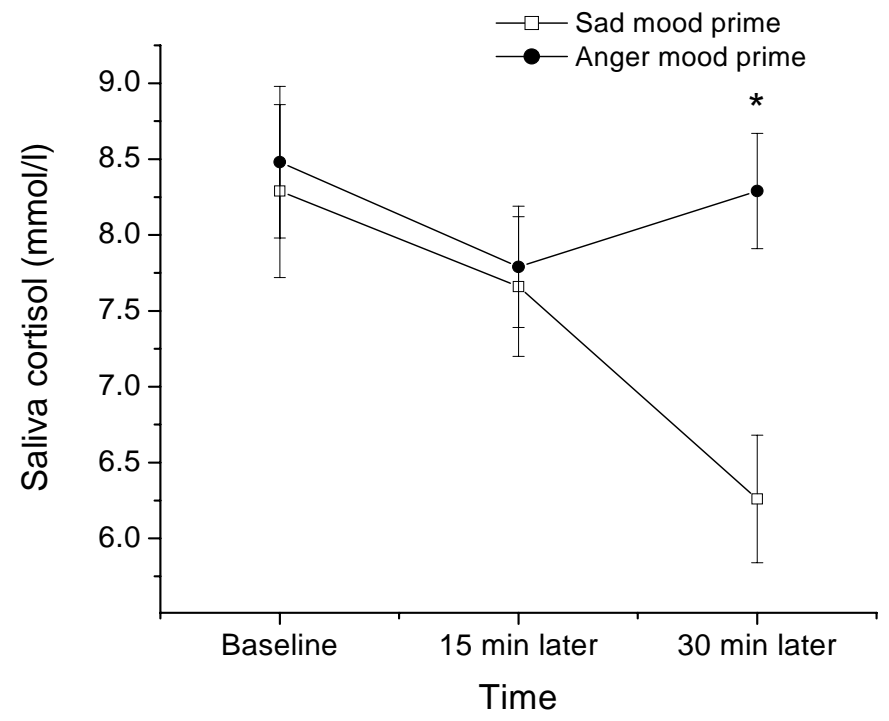

Fig. (1). Cortisol levels $( \pm$ SEM) at baseline, $15 \mathrm{~min}$ and $30 \mathrm{~min}$ following the discrimination event as a function of mood prime (sad vs anger). $* \mathrm{p}<.01$ relative to the anger mood prime. ${ }^{\mathrm{O}} \mathrm{p}<.05$ relative to baseline.

To assess whether cortisol responses were moderated by perceptions of control, hierarchical regression analyses were conducted to predict cortisol changes (i.e., proportion of change at 15 and 30 min following discrimination relative to baseline). Perceived control significantly moderated the effects of mood prime on cortisol changes both $15 \mathrm{~min}$, $R_{\text {cha }}^{2}=.121, F(1,49)=7.09, p<.01$, and 30 min following the discrimination event, $R_{\text {cha }}^{2}=.095, F(1,49)=6.25, p<.05$. Specifically, when women were primed to be sad, perceived control was not related to cortisol reactivity $(\beta s=-.19,-.16$, $n s$, respectively), whereas, among women primed to be angry, perceptions of control were associated with greater cortisol reactivity $(\beta s=.48, .45, p s<.01$, respectively). A comparable set of hierarchical regression analyses indicated that neither the direct nor moderating effects of hostility on cortisol reactivity were significant.

\section{Systolic Blood Pressure}

SBP varied significantly over the experimental session, $F(3,179)=5.69, p<.001, \eta^{2}=.091$, and pairwise comparisons indicated a significant increase of SBP following the discrimination event (see Fig. 2, top). The extent to which SBP returned to resting levels (30 min following the discrimination) was moderated by mood prime, $F(1,58)=4.00, p<.05$. As seen in Fig. (2), women's SBP remained high if they had been primed to feel sad, whereas those women primed to feel angry returned to resting levels.

To assess whether SBP reactions were moderated by hostility or perceptions of control, regression analyses were conducted to predict proportional changes of SBP immediately and $30 \mathrm{~min}$ following the discrimination event. Hostility demonstrated a significant interaction with mood prime on changes of SBP immediately following the discrimination event, $R_{\text {cha }}^{2}=.070, F(1,55)=4.24, p<.05$. Specifically, when women were primed to be sad, levels of hostility were not related to SBP $(\beta=-.13, n s)$, whereas, among women primed to be angry, levels of hostility were associated with increased SBP following the discrimination event $(\beta=.43, p<.05)$. Perceived control was not a significant direct or moderating predictor of SBP alterations.

\section{Diastolic Blood Pressure}

As seen in Fig. (2) (bottom), DBP changed significantly over the session, $F(3,162)=23.23, p<.001, \eta^{2}=.301$. Pairwise comparisons indicated that, although the mood priming task induced a mild increase of DBP ( $\left.p_{\text {corrected }}=.056\right)$, women showed the greatest DBP rise immediately following the discrimination event, and partial normalization after $30 \mathrm{~min}$, in that DBP levels dropped, but still remained higher than those evident at baseline.

Regression analyses indicated that neither hostility nor perceptions of control were related to DBP, and they did not moderate the effects of mood prime.

\section{Heart Rate}

Heart rate did not vary significantly over the course of the experimental session, nor did it interact with mood prime, $F_{\mathrm{s}}<1$. Regression analyses indicated that hostility was directly related to an increase of heart rate immediately following the discrimination event, $\beta=.32, R^{2}=.100, F(1,59)=$ $6.55, p<.05$. Although the interaction with mood prime was not significant, given the differential relations between hostility and SBP, the simple relations between hostility and heart rate among women primed to sad vs. angry were ex- 
plored. As with SBP, the relation between hostility and increased heart rate following discrimination was significant when women were primed to feel angry $(\beta=.44, p<.01)$, but not when primed to feel sad $(\beta=.18, n s)$. Perceptions of control were not associated with changes of heart rate.
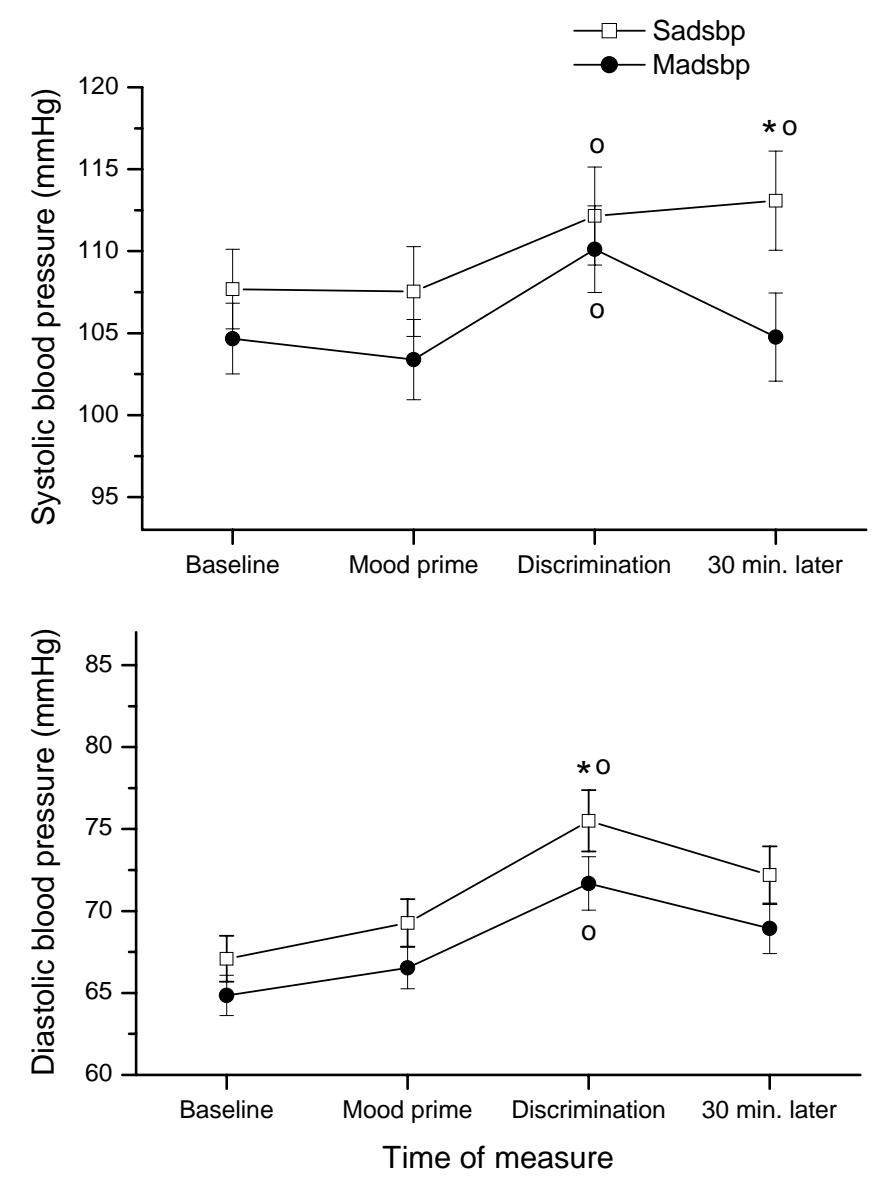

Fig. (2). Systolic (top) and diastolic (bottom) blood pressure $( \pm$ SEM) as a function of mood prime (sad vs anger). Measurements were taken at baseline and then again after the mood prime, the discrimination experience, and finally $30 \mathrm{~min}$ after the discriminatory experience. ${ }^{*} \mathrm{p}<.01$ relative to the anger mood prime. ${ }^{O} \mathrm{p}<$ .05 relative to baseline.

\section{Relations among Outcome Variables}

To assess the relations between the various outcome measures, patterns of zero-order correlations between selfreported mood, perceived discrimination, and the physiological stress indices were examined. None of the self-report indices was correlated with the physiological variables. Moreover, although the cortisol ratios at 15 and 30 min were positively correlated with one another $(r=.44, p<.01)$, cortisol ratios were not significantly related to any of the cardiac variables. Each of the cardiac variables was positively correlated from 1 to $30 \mathrm{~min}$ following the discrimination event (SBP $r=.46, p<.001$; DBP $r=.50, p<.001$; heart rate $r=.45$, $p<.001)$. Further, $1 \mathrm{~min}$ after the event DBP was related to SBP $(r=.31, p<.05)$ and heart rate $(r=.35, p<.05)$, although the latter two indices were not related $(r=.10, n s)$. None of the cardiac measures was significantly correlated with one another $30 \mathrm{~min}$ following the event.

\section{DISCUSSION}

Experiences of discrimination among members of minority groups, including women, have been linked to compromised psychological and physical well-being [1,2]. Given that discrimination is experienced on a persistent basis, such reactivity may have implications for well-being. Of particular interest in the present investigation were the effects of an acute instance of sex discrimination on stress reactivity, reflected by cortisol and cardiovascular responses. In addition, as group members likely bring with them prepotent emotional responses to particular events, the moderating role of an anger mood prime (vs. sadness) was assessed. As expected, an acute experience of discrimination and mood variations influenced both cortisol and cardiovascular responses.

As indicated earlier, although discrimination ordinarily elicits anger, other individual difference processes (e.g., threat sensitivity) are also brought to the situation, which might influence the levels of anger experienced and the inderindividual variability that is often evident. Thus, by priming anger, the variability in the extent to which it is experienced might be diminished, whereas it was expected that priming sadness, which is regarded as a 'passive' emotion, ought to diminish the activating properties of anger. As such, this comparison to sadness allows for a clearer examination of the potential influence of anger on physiological reactivity to discrimination (relative to a no-priming condition, in which discrimination would ordinarily still lead to anger). Based on both the self-report manipulation check, and the observed decline of cortisol among women primed to feel sad, it seems that this approach was effective.

Following a discrimination event, cortisol levels diminished among women primed to feel sad. This pattern of decline was comparable to that observed as a matter of course over a test session [30,79]. In contrast to the responses elicited when sadness was primed, among women who were exposed to discrimination following an anger mood prime, cortisol levels remained elevated. Clearly, discrimination alone was not responsible for the sustained elevation of cortisol levels, but instead this reaction was dependent upon the prepotent anger that accompanied the event.

It has been maintained that elevated neuroendocrine responses to a stressor reflect an adaptive response to meet environmental demands $[13,15,44]$, and that such responses were moderated by previous experiences as well as characteristics of the stressor experience, including predictability, ambiguity, chronicity and controllability [24]. It was observed that participants' perceptions of having some degree of control over the situation influenced the cortisol response, but this relation was only evident when they were primed to feel angry. Importantly, although stressor controllability has often been associated with limited neurochemical reactivity in response to stressors $[25,80]$, in the present investigation, among women who were angered, cortisol ratios at 15 and 30 min following the discrimination event were directly related to greater perceived control. As indicated earlier, control in the present investigation was not operationally defined in a manner comparable to that of most laboratory challenges (i.e., wherein outcomes are or are not contingent on particular responses). Rather, consistent with research examining responses to discrimination, controllability was considered in 
terms of the perceived efficacy of potential efforts to rectify their already failed status. It may be that anger plays an adaptive motivating role when the individual feels empowered to engage or deal with the situation [81], and elevated cortisol may be fundamental to this process, ostensibly acting in a preparatory capacity [13]. Of course, the correlational nature of the present results pertaining to control perceptions precludes causal inferences being made. Yet, provided that behavioral reactions attenuate the discrimination, or remove the individual from the situation, the elevated cortisol might be implicated in an adaptive process that serves the individual's best interests.

Despite the potential adaptive value of cortisol elevations, it is important to consider whether (a) the response to a given stressor is sustained or shows a relatively rapid return to baseline or resting levels, and (b) the stressor occurs acutely or is experienced on an ongoing or repeated basis. Repeated unpredictable stressor experiences together with extended cortisol elevations may, as indicated earlier, have adverse consequences [14]. In the present study, however, cortisol was not determined beyond $30 \mathrm{~min}$, and hence, the rate of normalization in response to such events remains unknown. Further, as women who were primed to feel angry exhibited a sustained cortisol response throughout the test session, coupled with the likelihood women encounter incidents of discrimination on a day-to-day basis, the altered cortisol response might raise concerns regarding longer-term well-being.

Given that discrimination may be a fairly potent psychosocial stressor and has been aligned with vulnerability to cardiovascular disease, particularly among African Americans $[1,3,18,19]$, it was anticipated that an acute discrimination event would promote elevated blood pressure and heart rate among women. As previously found [60,61], both SBP and DBP levels increased following the discrimination event. This was the case irrespective of the nature of the mood priming manipulation (sad vs. angry), suggesting that being subjected to an experience of discrimination was sufficient to increase blood pressure. Although elevated cardiac reactivity, like HPA activation, serves in an adaptive capacity, the extent of the response and the rates of normalization may serve as markers of vulnerability to cardiovascular illness $[55,82]$. In the present study, cardiac measures taken $30 \mathrm{~min}$ following the discrimination event indicated that although DBP had declined, it had still not reached resting levels. Interestingly, among women primed to feel angry, SBP had normalized by this time, but among women primed to feel sad, SBP levels remained high. It is noteworthy, in this regard, that the subjective feelings of sadness that were reported in this priming condition were accompanied by selfreports of anxiety. Thus, it may be that anxiety, rather than sadness per se, was responsible for the sustained SBP elevations. In fact, anxiety has been linked to slower recovery of SBP and DBP in a laboratory context [83], and so there was no a priori reason to believe that this effect would only be evident for SBP in the present study.

In the present study, trait hostility was not directly related to blood pressure, but was found to interact with the mood primed. Specifically, among women primed to feel angry, greater hostility was associated with higher SBP reactivity, as well as increased heart rate, immediately following the discrimination event. This is consistent with the possibility that anger and hostility are not redundant, but may synergistically influence cardiovascular reactivity $[48,62]$. To be sure, the discrimination manipulation in the present study represented a relatively limited experience, and was presented to a relatively young, healthy sample of women. The more important question is whether sex discrimination that occurs on a day-to-day basis and across different venues has a comparable and cumulative impact on women's health and well-being. All things considered, the present findings raise the possibility that repeated discrimination experiences that provoke anger may render women, particularly those high in trait hostility, at increased risk for cardiovascular problems. Of course, among minority women who experience discrimination due to multiple group memberships (e.g., race and sex), such double jeopardy may engender still greater risk for illness [65].

The characteristics of discrimination typify stressors that are likely to render the individual vulnerable to pathology (i.e., it is frequently unpredictable, occurs on a chronic basis, and often is ambiguous in intent). In any given situation, the impact of a stressor on HPA and cardiovascular indices may vary, and reactions to a given event may have different implications depending on the physiological system being assessed. Although these two systems may show common response patterns under some stressor conditions, they might also vary in a stressor-specific and time-linked fashion $[13,82,84]$, particularly as cardiovascular changes would be expected to occur almost immediately after a stressor, whereas cortisol variations would not be detected until 10-15 min later. Indeed, the measures of reactivity of these systems were not correlated, and the mood prime resulted in different reactions with respect to the HPA (cortisol) and cardiac output, and the individual difference characteristics that moderated these responses were also distinct. In this regard, although hostility was implicated in SBP and heart rate responses, perceptions of control were uniquely associated with cortisol reactivity. The former was somewhat surprising as other investigators have noted that actual or perceived control was associated with reduced blood pressure and heart rate reactions $[26,52]$. The reasons for these differential outcomes is uncertain, but it will be recalled that in the present investigation, the stressor itself (i.e., discrimination), which was uncontrollable, was experienced by all participants, and it is possible that it was this aspect of the stressor, rather than perceived control regarding the ability to rectify the situation, that prompted the blood pressure changes.

In summary, it appears that features of an acute discrimination event within a laboratory context were sufficient to promote cardiovascular and corticoid alterations like those associated with more traditional experimental stressors. As well, it seemed that physiological responses to discrimination involved the complex interplay among dispositional characteristics, antecedent mood states, as well as appraisals of the extent to which they had control over rectifying the situation. It ought to be underscored that the present investigation was one that exposed women to a blatant gender discrimination event. In many instances the events that group members experience are not as blatant, creating considerable uncertainty that could either diminish or exacerbate reactivity. Furthermore, as the stress responses of women may differ from those of men $[85,86]$, it remains uncertain whether 
responses to the forms of discrimination experienced by both genders (e.g., based on race, religion, sexual orientation, etc.) would be linked to the same biological processes and outcomes.

\section{ACKNOWLEDGEMENTS}

This research was supported by grants from the Canadian Institutes of Health Research and the Social Sciences and Humanities Research Council of Canada. Hymie Anisman holds a Canada Research Chair in Neuroscience.

\section{ABBREVIATIONS}

DBP $=$ Diastolic blood pressure
HPA $=$ Hypothalamic-pituitary-adrenal
SBP $=$ Systolic blood pressure

\section{REFERENCES}

[1] Clark R, Anderson NB, Clark VR, Williams R . Racism as a stressor for African Americans. A biopsychosocial model. Am Psychol 1999; 54: 805-816.

[2] Klonoff A, Landrine H, Campbell R. Sexist discrimination may account for well-known gender differences in psychiatric symptoms. Psychol Wom Quart 2000; 24: 93-99.

[3] Kwate NO, Valdimarsdottir HB, Guevarra JS, Bovbjerg DH. Experiences of racist events are associated with negative health consequences for African American women. J Natl Med Assoc 2003; 95 : 450-460.

[4] Mays VM, Cochran SD. Mental health correlates of perceived discrimination among lesbian, gay, and bisexual adults in the United States. Am J Public Health 2001; 91: 1869-1876.

[5] Whitbeck LB, McMorris BJ, Hoyt DR, Stubben JD, Lafromboise T. Perceived discrimination, traditional practices, and depressive symptoms among American Indians in the upper midwest. J Health Soc Behav 2002; 43: 400-418.

[6] Williams DR, Neighbors HW, Jackson JS. Racial/ethnic discrimination and health: Findings from community studies. A J Public Health 2003; 93: 200-208.

[7] Wyatt SB, Williams DR, Calvin R, Henderson FC, Walker ER, Winters K. Racism and cardiovascular disease in African Americans. A J Med Sci 2003; 325: 315-331.

[8] Allison KW. Stress and oppressed social category membership. In: Swim JK Stangor C, Eds. Prejudice: The Target's Perspective, San Diego: Academic Press 1998; pp.145-170.

[9] Major B, O'Brien LT. The social psychology of stigma. Annu Rev Psychol 2005; 56: 393-421.

[10] Matheson K, Jorden S, Anisman H. Relations Between Trauma Experiences and Psychological, Physical and Neuroendocrine Functioning Among Somali Refugees: Mediating Role of Coping with Acculturation Stressors. J Immigr Minor Health 2007 Oct 16; [epub ahead of print]

[11] Swim JK, Cohen LL, Hyers LL. In: Swim JK, Stangor C, Eds. Prejudice: The Target's Perspective, San Diego: Academic Press 1998; pp.38-61.

[12] Goldstein DS, McEwen B. Allostasis, homeostats, and the nature of stress. Stress 2002; 5: 5-58.

[13] Sapolsky RM, Romero LM, Munck AU. How do glucocorticoids influence stress responses? Integrating permissive, suppressive, stimulatory, and preparative actions. Endocr Rev 2000; 21: 55-89.

[14] McEwen BS. Mood disorders and allostatic load. Biol Psychiatry 2003; 54: 200-207.

[15] McEwen BS. Allostasis and allostatic load: Implications for neuropsychopharmacology. Neuropsychopharmacology 2000; 22: 108124.

[16] Broman CL. The health consequences of racial discrimination: A study of African Americans. Ethn Dis 1996; 6: 148-153.

[17] Clark R. Self-reported racism and social support predict blood pressure reactivity in Blacks. Ann Behav Med 2003; 25: 127-136.
[18] Gee GC. A multilevel analysis of the relationship between institutional and individual racial discrimination and health status. Am J Public Health 2002; 92: 615-623

[19] Karlsen S, Nazroo JY. Relation between racial discrimination, social class, and health among ethnic minority groups. Am J Public Health 2002; 92: 624-631.

[20] Landrine H, Klonoff EA, Gibbs J, Manning V. (1995). Physical and psychiatric correlates of gender discrimination: An application of the schedule of sexist events. Psychol Wom Quart 1995; 19: 473-492.

[21] Thompson VL. Racism: Perceptions of distress among African Americans. Community Ment Health J 2002; 38: 111-118.

[22] Herrald MM, Tomaka J. Patterns of emotion-specific appraisal, coping, and cardiovascular reactivity during an ongoing emotional episode. J Pers Soc Psychol 2002; 83: 434-450.

[23] Mackie DM, Devos T, Smith ER. Intergroup emotions: Explaining offensive action tendencies in an intergroup context. J Pers Soc Psychol 2000; 79: 602-616.

[24] Anisman H, Matheson K. Anhedonia and depression: Caveats of animal models. Neurosci Biobehav Rev 2005; 29: 525-546.

[25] Dickerson SS, Kemeny ME. Acute stressors and cortisol responses: A theoretical integration and synthesis of laboratory research. Psychol Bull 2004; 130: 355-391.

[26] Peters ML, Godaert GL, Ballieux RE, van Vliet M, Willemsen JJ, Sweep FC, Heijnen CJ. Cardiovascular and endocrine responses to experimental stress: Effects of mental effort and controllability. Psychoneuroendocrinology 1998; 23: 1-17.

[27] Major B, Schmader T. Coping with stigma through psychological disengagement. In: Swim JK, Stangor C, Eds. Prejudice. The Target's Perspective, San Diego: Academic Press 1998; pp.219-241.

[28] Wright SC, Taylor DM, Moghaddam FM. Responding to membership in a disadvantaged group from acceptance to collective protest. J Pers Soc Psychol 1990; 58: 994-1003.

[29] Kappen DM, Branscombe N. The effects of reasons given for ineligibility on perceived gender discrimination and feelings of injustice. Br J Soc Psychol 2001; 40: 295-313.

[30] Matheson K, Cole B. Coping with a threatened group identity: Psychological and neuroendocrine responses. J Exp Soc Psychol 2004; 40: 777-786.

[31] Swim JK, Hyers LL, Cohen LL, Fitzgerald DC, Bylsma WH. African American college students' experiences with everyday racism: Characteristics of and responses to these incidents. J Black Psychol 2003; 29: 38-67.

[32] Gill R, Matheson K. Responses to discrimination: The role of emotion and expectations for emotional regulation. Pers Soc Psychol Bull 2006; 32: 149-161.

[33] Louis WR, Taylor DM. From passive acceptance to social disruption: Towards an understanding of behavioural responses to discrimination. Can J Behav Sci 1999; 31: 19-28.

[34] van Zomeren M, Spear R, Fischer AH, Leach CW. Put your money where your mouth is! Explaining collective action tendencies through group-based anger and group efficacy. J Pers Soc Psychol 2004; 87: 649-664.

[35] Scherer KR. Appraisal considered as a process of multilevel sequential checking. In: Scherer KR, Schorr A, Johnstone T, Eds. Appraisal Processes in Emotion: Theory, Methods, Research, New York: Oxford University Press 2001; pp.92-120.

[36] Smith HJ, Kessler T. Group-based emotions and intergroup behavior: The case of relative deprivation. In: Tiedens LZ, Leach CW, Eds. The Social Life of Emotions, Cambridge, UK: Cambridge University Press 2004; pp. 292-313.

[37] Bodenhausen GV, Mussweiler T, Gabriel S, Moreno KN. Affective influences on stereotyping and intergroup relations. In: Forgas JP, Ed. Handbook of Affect and Social Cognition, Hillsdale, NJ: Lawrence Erlbaum Associates 2001; pp.319-343.

[38] DeSteno D, Dasgupta N, Bartlett MY, Cajdric A. Prejudice from thin air: The effect of emotion on automatic intergroup attitudes. Psychol Sci 2004; 15: 319-324.

[39] Mendoza-Denton R, Downey G, Purdie VJ, Davis A, Pietrzak J. Sensitivity to status-based rejection: Implications for African American students' college experience. J Pers Soc Psychol 2002; 83: 896-918. 
[40] Schmitt MT, Branscombe NR, Postmes T. Women's emotional responses to the pervasiveness of gender discrimination. Eur J Soc Psychol 2003; 33: 297-312.

[41] Kirschbaum C, Hellhammer DH. Salivary cortisol in psychoneuroendocrine research: Recent developments and applications. Psychoneuroendocrinology 1994; 19: 313-333.

[42] Michaud K, Matheson K, Kelly O, Anisman H. (2007) Impact of Naturalistic Stressors on Cortisol Levels: A Meta-Analysis. Stress. In press.

[43] Miller GE, Chen E, Zhou E. If it goes up, must it come down? Chronic stress and the hypothalamic-pituitary-adrenal axis in humans. Psychol Bull 2007;133: 25-45.

[44] deKloet ER, Oitzl MS, Joels M. Stress and cognition: Are corticosteroids good or bad guys? Trends Neurosci 1999; 22: 422-426.

[45] Cacioppo JT, Malarkey WB, Kiecolt-Glaser JK, Uchino BN, Sgoutas-Emch A, Sheridan JF, et al. Heterogeneity in neuroendocrine and immune responses to brief psychological stressors as a function of autonomic cardiac activation. Psychosom Med 1995; 57: 154164.

[46] DeVente W, Olff M, VanAmsterdam JG, Kamphuis JH, Emmelkamp PM. Physiological differences between burnout patients and healthy controls: Blood pressure, heart rate, and cortisol responses. Occup Environ Med 2003; 60(Suppl 1): i54-61.

[47] Kok FW, Westenberg HG, Thijssen JH, van Ree JM. Endocrine and cardiovascular responses to a series of graded physical and psychological stress stimuli in healthy volunteers. Eur Neuropsychopharmacol 1995; 5: 515-522.

[48] Fredrickson BL, Maynard KE, Helms MJ, Haney TL, Siegler IC, Barefoot JC. Hostility predicts magnitude and duration of blood pressure response to anger. J Behav Med 2000; 23: 229-243.

[49] Miller TQ, Smith TW, Turner CW, Guijarro ML, Hallet AJ. A meta-analytic review of research on hostility and physical health. Psychol Bull 1996; 119: 322-348.

[50] Rhodes RD, Harrison DW, Demaree A. Hostility as a moderator of physical reactivity and recovery to stress. Int J Neurosci 2002; 112: 167-186.

[51] Suls J, Wan CK. The relationship between trait hostility and cardiovascular reactivity: a quantitative review and analysis. Psychophysiol 1993; 30: 615-626.

[52] Gerin W, Litt MD, Deich J, Pickering TG (1995). Self-efficacy as a moderator of perceived control effects on cardiovascular reactivity: Is enhanced control always beneficial? Psychosom Med 1995; 57: 390-397.

[53] Garcia LA, del Paso GA, Robles H, Vila J. Relative effects of harassment, frustration, and task characteristics on cardiovascular reactivity. Int J Psychophysiol 2003; 47:159-173.

[54] Lavoie KL, Miller SB, Conway M, Fleet RP. Anger, negative emotions, and cardiovascular reactivity during interpersonal conflict in women. J Psychosom Res 2001; 51: 503-512.

[55] Matthews KA, Gump BB, Owens JF. Chronic stress influences cardiovascular and neuroendocrine responses during acute stress and recovery, especially in men. Health Psychol 2001; 20: 403-410.

[56] Futterman LG, Lemberg L. Anger and acute coronary events. Am J Crit Care 2002; 11: 574-576.

[57] Rutledge T, Hogan BE. A quantitative review of prospective evidence linking psychological factors with hypertension development. Psychosom Med 2002; 64: 758-766.

[58] Schwartz AR, Gerin W, Davidson KW, Pickering TG, Brosschot $\mathrm{JF}$, Thayer JF, et al. Toward a causal model of cardiovascular responses to stress and the development of cardiovascular disease. Psychosom Med 2003; 65: 22-35.

[59] Kop WJ. The integration of cardiovascular behavioral medicine and psychoneuroimmunology: New developments based on converging research fields. Brain Behav Immun 2003; 17: 233-237.

[60] Din-Dzietham R, Nembhard WN, Collins R, Davis SK. Perceived stress following race-based discrimination at work is associated with hypertension in African-Americans. The metro Atlanta heart disease study, 1999-2001. Soc Sci Med 2004; 58: 449-461.

[61] Fang CY, Myers HF. The effects of racial stressors and hostility on cardiovascular reactivity in African American and Caucasian men. Health Psychol 2001; 20: 64-70.

[62] Suarez EC, Harlan E, Peoples MC, Williams RB Jr. Cardiovascular and emotional responses in women: The role of hostility and harassment. Health Psychol 1993; 12: 459-468.
[63] Bello N, Mosca L. Epidemiology of coronary heart disease in women. Prog Cardiovas Dis 2004; 46: 287-295.

[64] Tsang TS, Barnes ME, Gersh BJ, Hayes SN. Risks of coronary heart disease in women: current understanding and evolving concepts. Mayo Clin Proc 2000; 75: 1289-1303.

[65] Guyll M, Matthews KA, Bromberger JT. Discrimination and unfair treatment: Relationship to cardiovascular reactivity among African American and European American women. Health Psychol 2001; 20: $315-325$.

[66] Crosby F. The denial of personal discrimination. Am Behav Psychologist 1984; 27: 371-386.

[67] Foster MD, Matheson K. Perceiving and responding to the personal/group discrimination discrepancy. Pers Soc Psychol Bull 1999; 25: 1319-1329.

[68] Major B, Quinton WJ, McCoy SK. Antecedents and consequences of attribution to discrimination: Theoretical and empirical advances. In: Zanna M, Ed. Advances in Experimental Social Psychology, San Diego: Academic Press 2002, pp. 251-330.

[69] Taylor DM, Wright SC, Moghaddam FM, Lalonde RN. The personal/group discrimination discrepancy: Perceiving my group, but not myself to be a target of discrimination. Pers Soc Psychol Bull 1990; 16: 254-262.

[70] Brondolo E, Rieppi R, Kelly KP, Gerin W. Perceived racism and blood pressure: a review of the literature and conceptual and methodological critique. Ann Behav Med 2003; 25: 55-65.

[71] Williams DR, Neighbors HW. Racism, discrimination and hypertension: Evidence and needed research. Ethn Dis 2001; 11: 800816.

[72] Lemerise EA, Dodge KA. (1993). The development of anger in hostile interactions. In: Lewis M, Haviland JM, Eds. Handbook of Emotions, New York: Guilford 1993; pp. 537-546.

[73] Robins, C. (1988). Development of experimental mood induction procedures for testing person event interaction models of depression. J Clin Psychol, 44, 938-963.

[74] Schmidt-Reinwald A, Pruessner JC, Hellhammer DH, Federenko I, Rohleder N, Schurmerer TH, et al. The cortisol response to awakening in relation to different challenge tests and a 12-hour cortisol rhythm. Life Sci 1999; 64: 1653-1660.

[75] Zwick WR, Velicer WF. Comparison of five rules for determining the number of components to retain. Psychol Bull 1986; 99: 432442.

[76] Taylor DM, Wright SC, Ruggiero KM. The personal/group discrimination discrepancy: responses to experimentally induced personal and group discrimination. J Soc Psychol 1991; 131: 847-858.

[77] Ruggiero KM, Taylor DM. Why minority group members perceive or do not perceive the discrimination that confronts them: the role of self-esteem and perceived control. J Pers Soc Psychol 1997; 72: 373-389.

[78] Buss AH, Durkee A. An inventory for assessing different kinds of hostility. J Counsult Psychol 1957; 21: 343-349.

[79] Miller GE, Rohleder N, Stetler C, Kirschbaum C. Clinical depression and regulation of the inflammatory response during acute stress. Psychosom Med 2005; 67: 679-687.

[80] Anisman H, Zalcman S, Shanks N, Zacharko RM. Multisystem regulation of performance deficits induced by stressors: An animal model of depression. In: Boulton A, Baker G, Martin-Everson M, Eds. Neuromethods: Animal Models of Psychiatry, II , New Jersey: Humana Press 1991; pp. 1-59.

[81] Bandler R Keay K, Floyd N, Price J. Central circuits mediating patterned autonomic activity during active vs. passive emotional coping. Brain Res Bull 2000; 53: 95-104.

[82] Roy MP, Steptoe A, Kirschbaum C. Life events and social support as moderators of individual differences in cardiovascular and cortisol reactivity. J Pers Soc Psychol 1998; 75: 1273-1281.

[83] Vitaliano PP, Russo J, Paulsen VM, Bailey, SL. Cardiovascular recovery from laboratory stress: biopsychosocial concomitants in older adults. J Psychosom Res 1995; 39: 361-377.

[84] Cohen S, Hamrick N, Rodriguez MS, Feldman PJ, Rabin BS, Manuck SB. The stability of and intercorrelations among cardiovascular, immune, endocrine, and psychological reactivity. Ann Behav Med 2000; 22: 171-179.

[85] Klein LC, Corwin EJ. Seeing the unexpected: How sex differences in stress responses may provide a new perspective on the manifes- 
tation of psychiatric disorders. Curr Psychiatry Rep 2002; 4: 441448.

[86] Traustadottir T, Bosch P, Matt KS. Gender differences in cardiovascular and hypothalamic-pituitary-adrenal axis responses to psy- chological stress in healthy older adult men and women. Stress 2003; 6: 133-140.

[87] Beck AT, Beck RW. Screening depressed patients in family practice. A rapid technique. Postgrad Med 1972; 52: 81-85.

(C) Matheson et al.; Licensee Bentham Open.

This is an open access article distributed under the terms of the Creative Commons Attribution License (http://creativecommons.org/licenses/by/2.5/), which permits unrestrictive use, distribution, and reproduction in any medium, provided the original work is properly cited. 